\title{
Sense of Harmony in Chinese Traditional Culture
}

\author{
YAN Lian-fu \\ Xi’an Jiaotong University, Xi’an, China
}

\begin{abstract}
A harmonious culture is not supposed to be a monologue of one voice but a dialogue of many voices. Chinese ancient culture doesn't mean one-dimensional notion of nature transforming to human like that in western philosophy, but means the hiding and dialogue between the nature and the human body. Specifically, Wen hua just means a dialogue based on the body. Heaven Unitfied With the Human and Complement of Confucianism and Taoism provide this opinion. Sense of Harmony in Chinese traditional culture provides us important ideological resources for building a harmonious culture and promoting the harmonious development of mankind.

Keywords: Chinese ancient culture, harmony, heaven unitfied with the human, Complement of Confucianism and Taoism
\end{abstract}

Harmony as culture from its external correlatives or its internal mechanism, should be considered as a dialogue in a way of diverse voices more than a mode of soliloquy. When we put our attention to the Chinese ancient classics, it is not difficult to find that Chinese traditional culture which inclined to the realization and discovery of the body with the encompassment of dialogue and the sense of harmonies, is entirely different from the western traditional culture by the thinking method expressed as "Nature facing the human being to be produced" throughout the process of modifying the nature. Chinese traditional culture attempts to accompany the interactive culture with the human being, deal with the nature in a harmonious sense by adapting himself to natural environment and by making natural environment benefit for himself.

\section{Culture as Dialogue}

Culture in Western world set its logic basements and thinking methods on the dichotomy at its source. Dichotomy thought is embodied in the relationship between human and nature, it means human is subjective and nature is objective, and therefore, western culture is characterized by anthropocentrism. In the relationship between body and mind, subject-object dichotomy thought means mind is subjective and body is objective, mind and body is separated, thus western culture withal characterized by Conciousism. There are many words corresponding to Culture in terms of origins. Culture in Latin is a verb, which means cultivate, reside, practise and so on with its distinctive features of nature remodelling. In other Indo-European languages like English and France, culture also means cultivate and plant. Culture means, above all, people's idea conquering and reshaping nature, and then it extends to edify human nature and moral upbringing. Noted western philosophers, consciously and unconsciously, demonstrate and illustrate Subject-object dichotomy. From "man is the measure of all things" by Protagoras, "Know yourself” by Socrates, to "the Human Being's Legislation for Nature" and "nature cultivated with humanity" by Kant, they all show the subjectivity dominant position of

YAN Lian-fu, Ph.D., Professor, Marxism School, Xi’an Jiaotong University. 
human beings to the nature. From "ego cogito, ergo sum" by Descartes, to "The absolute idea" by Hegel, then to "My will is the highest existence" by Schopenhauer, and so on, their thoughts all reflect the notion that mind controls and rules the body. Hence, one-dimensional characteristic apparently dominates in the western culture.

Different from the western culture, the Chinese ancient culture originates from and ultimately orients to subject-object dichotomy (combination of subject and object). As the Chinese people could see, human beings should never conflict with nature, and body and mind should never separate. The concept of Chinese ancient culture, innately contains the dialogues between human and nature, and between body and mind. According to ancient books, wen (文) originally means the texture of interweaved colors. XC・ii in Book of Changes (《易·系 辞下》) states, this way is marked by changes and movements, and hence we have the imitative lines. Those lines are of different grades and hence we designate them from their component elements. These are mixed together, and elegant forms arise. Yo Ki in The Li Ki (《礼记·乐记》) comments, the five colours form a complete and elegant whole without any confusion. Shuo Wen Jie Zi (《说文解字》) interprets, Wen should be considered on the viewpoints of that the heaven and the earth is in the sense of being temporal and spatial. Accordingly, Wen have several extended implications as well, embodying rhetoric, embellishment and cultivation, as a counterpart of zhi (质) and shi (实). Therefore, Shun of The Shu says, Wen was saw in the perspective of considered the heaven and earth from up to down in latitude-longitude. And The sayings of Confucius VI (《论语·雍也》) states, nature outweighing art begets roughness; art outweighing nature begets pedantry. Art and nature well blend make a gentleman. Here, as the texture of things, why is Wen closely linked to human beings, and then evolved to Culture which distinguishes human beings from animals? Our answer is: Because the body (身体) of human can play an important bridge role between Wen and human, it serves as a platform for dialogue between body and mind, and between body and nature.

In ancient China, besides the texture of jade, Wen also means tattoo when referring to humans.

The 13th Year of Ai-Gong in Gu Liang Zhuan (《穀梁传·哀公十三年》) records, people cut their hair and tattoo themselves in Wu, a barbaric state, and notes that tatooing their bodies means Wen. The Original meaning of Wen is a faithful record of this historical phenomenon. Wang Kih in The $\mathrm{Li} \mathrm{Ki}$ (《礼记·王制》) gives an account that with disheveled hairs and tattoos, people who live in East are barbarian, and eat raw food. Han Nan Zi (《淮南子》) records, in the south of Jiuyi Mountains, people are less land-based and more water-based, They prefer keeping long hairs and dragon tattoos (Gao You 高诱 noted: People tattoo the figure with dragons and ink them. When they travel by water, dragons will not injure them, and so it calls tattoo mythical flood dragon). Shuo Yuan in The Article of FengShi (《说苑·奉使篇》) comments, people with dishevelled hairs says, our state, Yue (...) is located by the seaside. On guard against pirates, we also struggle with mythical flood dragon. We cut hair and tattoo dragons, which can make us look like sons of dragons, in order to elude the god of water. Geographica in Han Shu (《汉书·地理志》) states, Cantonese cut hairs and tattoo to avoid dragon disasters.

The reason why ancient Chinese think highly of tattoos, is that they consider tattoos to be good for their health. For example, ancient people who live in Yilou, they always resist the cold by daubing skin with lard. Afterwards, gradually they come to realize daubing body in this way is beautiful, and thus they daub body for aesthetic pleasure. More primitives draw images of animals (totems) on their skin, which are regarded as symbols of ancestors. Once a tattoo is accepted as a symbol of clan members, it becomes a regulation. Meanwhile, a tattoo has another meaning, that is, the sexual rights of primitives. Tattoo is closely related to adultness, and adultness is tightly linked to sexual rights. It follows that, because of start from the view of body, 
Wen that means texture is branded with human; Deriving from tattoos, production culture, aesthetic culture, religious culture and so on thrive.

Hua (华) originally means change, produce, and create. As it says in Free and Easy Wandering in Chuang Tzu (《庄子·逍遥游》), he becomes a bird whose name is Peng. XC・ii in Book of Changes says, there is an intercommunication of seed between male and female, and transformation in its living types proceeds. Su Wen in Huang Di Nei Jing ( 《黄帝内经》) says, change is eternal, and the tendency of development cannot be resisted. Kung Yung in The Li Ki (《礼记·中庸》) comments, he can assist the transforming and nourishing operations of heaven and earth. And so on. The extended meaning of Hua is, teaching and influencing people to correct evil doings and revert to good deeds. Shuo Wen explains, Hua means educate and enlighten. Zeng Yun ( 《增韵》) records, teaching is deify people by virtue. Teachers self-disciplined, students influenced, this way is Hua. In fact, the original meaning of Hua does not only mean the change of body, but also refers to the change of mind. In terms of the structure of Hua, the left side $\uparrow$ means human being, and the right side 七 which looks like the shape of human in a handstand means the change of body. Zheng Yun (《正韵》) says, all of these discourses and words can revive your lost heart, it means Hua is what you find the pure spirit by the power of the utterances. Obviously, Hua means the change of mind as well. Therefore, we can say that Wen merely means human tattooing their body to cover their weakness, while Hua further means the change of mind and body. Wen is human beings' transformation towards nature, while Hua is nature's transformation towards human beings.

According to Bi・Xiang in Book of Changes ( 《易·贲卦·象转》), where Wen and Hua are first used together, it says, (We see) the weak line coming and ornamenting the strong lines (of the lower trigram), and hence (it is said that ornament) should have free course. On the other hand, the strong line above ornaments the weak ones (of the upper trigram), and hence (it is said) that there will be little advantage, if (ornament) be allowed to advance (and take the lead). (This is illustrated in the) appearance of ornament the sky. Elegance and intelligence (denoted by the lower trigram) regulated by the arrest (denoted by the upper) suggest the observances that adorn human (society). We look at the ornamental figure of the sky, and thereby ascertain the changes of the seasons. We look at the ornamental observances of society, and understand how the process of transformation are accomplished all the under heaven. After the Western Han Dynasty, Wen and Hua is combined to be a word Wen Hua (文化) (meaning culture). For example, Zhi Wu in Shuo Yan (《说苑·指武》) says, it will be punished more heavily if the culture is unchanged; San Yue San Ri Qu Shui Shi Xu ( 《三月日 曲水诗序》) sates, influence folk custom by heavenly principles, promote culture to the masses; Supplemental poet of Wen Xuan (《文选》) says, if inner cultivated abilities were accumulated, the outer enterprises accomplished in leisure ways. In these examples, Wen Hua is the opposite meaning of nature, rusticity and barbarism. Wen Hua implies astronomy and humanity, and it includes not only nature but also civilization.

In western philosophy culture means the humanization of nature, nature transforming to human. It is a unidirectional human-centered transform to the nature. In contrast, the notion of Chinese ancient culture refers to the interaction between human and nature as well as mind integrated into body. It is a harmonious dialogue between mankind and nature. In short, Chinese ancient culture is dialogue. It is not only the dialogue between body and mind, but also the dialogue between nature and human. The ancient thought that the unity of nature and man and the confucianist's idea of complementary relationship between yin and yang well explicates and enriches the notion of Chinese ancient culture. 


\section{Dialogue Carried by the Body}

With the subject-object dichotomy as its premise, the western culture advocates the separation between mankind and nature. Dating back to ancient times, it tends to divide universe into two very different worlds. It separates mankind and nature, and thus causes the opposition between human and nature. Either the original sin in Christianity, which asks people to conquer nature and retify mistakes unyieldingly to redeem him/herself in order to acquire extraordinary power, or the notion of everything opposes to others in western philosophy that is based on the idea that separation between mankind and nature. People, staying away from the external world, observe and regard it to be objective. This has led to their attention to formal thinking and abstract thinking and strive for abstraction of certain simple notions in pure forms. Meanwhile, stress is laid on reasoning, i.e., deduction, abstraction, analysis, and science rationality brings out splendid triumph in front of nature. In consequence, however, the conflict between human and nature is growing, and the modernized crisis turns to be the core issue in western culture.

Based on the logic of combining the subject with the object, the Chinese traditional culture emphasizes the harmony of human and nature. As a precocious ecological theory, it is the essence of Chinese classical culture. Specifically, Chinese traditional culture, which derives from the human body, above all, does not pay close attention to the humanization of nature, i.e., so-called "nature transfoming to human" in the west which is caused by subject-object dichotomy and separation between mankind and nature. On the contrary, according to subject-object dichotomy, it focuses on the integrated and harmonious coexistence of mankind and nature. The harmony is not achieved through meditation and reasoning in western philosophy. Instead, it is accomplished by perceptual physical experience. The essence of Chinese ancient culture can be accounted as I act, therefore I am here instead of cogito ergo sum. Consequently, we can explicate the history of Chinese ancient culture in a very new way, by regarding Shang Shu as the original source of the harmonious coexistence or man and nature in Chinese ancient culture. It is not only on account that Shang Shu is the earliest record of this notion, but also that it helps to establish a religion about body by restoring the notion of Tian (天) by means of physical experience.

Shang Shu is the first record of human worship of Tian. In fact, such worship is worship of Tian simatized and rather than worship of Tian irrelevant to human. In ancient book Shang Shu, the word Sheng (身) in Sheng Jue Ming (身厥命) is the same as “イ”, which means God in Shuo Wen. In other words, the so-called God actually is the body itself that reveals in the behaviors of the body. All this shows that, as far as Chinese could see, either the universal Tian Tao (天道) or the ethical Ren Tao (人道) is Tao living with body. Beside, the radical and ultimate Shen Tao (神道) which dominates nature and human beings is also rooted in the body. Hence in Chinese ancient culture, the body is not only confined to the naturalistic flesh, but is also metaphorized to such words with highly abstract implications like embodiment, Tao body and Buddha body. Body is the starting point of the world, is the eternal place which Lao-tzu describes as, everlasting is lose but not lost, longevity is dead but not death. Therefore, the thought of heaven unitfied with the human is not only based on the most original meaning of body, but also has the extreme abstract symbolic meaning. The thought of heaven unitfied with the human means via body, human dialogue with natural and the universe dialogue with the human body. That is interaction between nature and mankind, as well as the influence between god and human.

Thereout, we can say that, the carrier of harmonious coexistence of human and nature is the body itself which can interconnect each other, rather than what Dong Zhongshu (董仲舒) states as Tian Tao and Ren Tao 
are interconnected by the ruler. The harmony is not designed to achieve abstract objectives, such as Tao will not change if Tian unchanged. Instead, it aims at interaction between Ren Tao and Tian Tao. Specifically, for mankind, it is embodied in self-cultivation. In Shang Shu, if you want to be upgraded, you must start from downgraded. If you want to travl a long distance, you must walk from the under-footing. No important than do it by yourself. The heaven fate accompany with you. Such self-cultivation thoughts lays a historical foundation for Chinese unique cultural tradition. Moreover, we see the sources of almost all creeds in later Chinese culture in Shang Shu as it explains $L i$ in detail, acknowledges Tao (道) and De (德), and advocates Cheng (诚) and Xin (信) and so on. Consequently, we can say Shang Shu is the first book of Chinese cultural history, and is the foremost book to interpret culture from the perspective of the body.

If we presume Shang Shu starts the Chinese culture in the view of the body, and lays a theoretical basis for the thought of unity of nature and man, Shang Shu and Zhou Li represents a golden age for Chinese ancient body culture. Shang Shu departs from the body, and creates comprehensive working mode of the world named as Tian Tao. Zhou Li sets out from body, and structures a rigorous operation mode for social culture named as Ren Tao. Shang Shu and Zhou Li both supplemente and perfect the thought of harmony of nature and mankind.

In the question of the world mode, it is a prevailing thought that God creates the world in the West. Book of Changes, however, holds a disparate view. Proceeding from XC •ii in Book of Changes, near at hand, in his own person, he found things for consideration, and the same at a distance, in things in general. It regards the body and behaviors as the origin of occurrences in the universe, and structures such a dynamic mode of cosmology named Tai Chi (太极), to be specific, XC•i in Book of Changes says, therefore in (the system of) the Yi there is the Grand Terminus, which produced the two elementary Form. Those two Forms produced the Four emblematic Symbols, which again produced the eight Trigrams. The eight trigrams served to determine the good and evil (issues of events), and from this determination was produced the (successful prosecution of the) great business (of life). The word Tai (太) in Tai Chi is extended from Da (大). According to Shi Gu in Guang Ya (《广雅·释诂》), Da means Tai. And in Xu Shen’s (许慎) Shuo Wen, Da, a pictographic character, looks like the shape of an able-bodiedman stretched. Hence, Tai Chi is the human body, as well the starting point of the world: Two Forms (两仪) refers to sexes, as well Yin and Yang, and heaven and earth; Four Images (四象) represents human limbs, as well the four directions of heaven and earth; the Diagram (卦) in The Eight Diagrams (八卦) implies human personally practice all the space and everything. When Book of Changes unifies occurrences of the universe with human beings, the universe is endowed with Yin and Yang like humans. In this way, Book of Changes starts from the view of body, and follows the principle of Yin intersected with Yang, "Communicate to be harmony" and "influence the whole creation", and builds a harmonious operation mode of the universe. The gist of Book of Changes lies in the mode it constructs from the body, while Zhou Li aims at deducing social ethics from the body. Such a process of deducing ethics standard follows the mode as recorded in Yi Zhuan (《易传》), i.e., When there were heaven and earth, then afterwards all things were produced. When all things were produced, then afterwards the male and female, the couples. When couples had children, there must be a relationship of father and son, which could soundly realize the connection of monarch-officials and establish the rules. The rule for the relation of husband and wife is that it should be long-enduing. Zhou $\mathrm{Li}$ take this thought a step further. In Zhou $\mathrm{Li}$, the characteristics of body culture are discussed in the following aspects. Firstly, by means of "turns round and seeks the cause of his failure in himself", Zhou Li retroactively restores social ethical rites to individuals who practice them in person. For 
example, Zhong Yong (《中庸》) says, when the archer misses the centre of the target, he turns round and seeks for the cause of his failure in himself; Zuo Zhuan ( 《左传》) says, gentlemen cherish his body; Ai Kung Wen in The Li Ki (《礼记·哀公问》) says, wherein it appears the greatest is in his respect for himself; Zhong Yong states, therefore the course of the superior man is rooted in his own character, and so on. Secondly, on this basis, Zhou $\mathrm{Li}$ puts forward for couples ways of getting along with each other based on the mechanism of sexes. Specifically, on the one hand, it is the prototype of social ethics that The way of the superior man may be found in its simple elements among common men and women (Zhong Yong); on the other hand, by way of the union of husband and wife, a set of clan communities and blood communities form in the society, and turn into a national model where families and the state are unified.

\section{Yin and Yang Reciprocal Completed by the Body}

The premise of western culture is the thought of subject-object dichotomy, however, from the perspective of mind and body, western culture is a culture whose core is consciousness. Consciousness is characterized with non-sexualness, as Zhang Xianglong (张祥龙) says, the western traditional prevailing philosophy is a nonsexual philosophy. Actually, the western traditional prevailing culture is a nonsexual culture as well. The Chinese traditional culture is then a culture, which regards the body as the core, and this characteristic just determine the Chinese traditional culture to be a culture, which emphasizes gender consciousness. In other words, subject-object dichotomy, on the other side, stresses Yin and Yang complementing each other, and male and female reinforcing one other. As two major sects of Chinese traditional culture, Confucianism and Taoism, which depart from the body, and center around the relationship between male and female, and Yin and Yang, respectively highlights male chauvinist culture which advocates Yang overcoming Yin, and feminist culture which underlines softness overcoming hardness.

Every important concept in Confucianism is connected with body. Confucian Analects abounds with insightful ideas and discussions, and the major points can be concluded in "turns round and seeks the cause of his failure in himself". Confucius attaches the utmost importance to self-cultivation in his life, and he puts much emphasis on learning, politics and life. All the three fields are carried out around body. In learning, Confucius stresses study and practice what you have learnt. Xi (习) is not only review books, but also put into practice; he puts forward study without pondering will cause bewilderment. Here, pondering is really not daydream, but means the reflection described in inquiring with earnestness and reflect with self-practice and that thrice daily I ask myself. In the field of politics, the person in the highest position should act with integrity. If he sets an good example, would others dare not to follow? Politics means practice as the saying, when a ruler's personal conduct is correct, he will be obeyed without the issuing of orders. If his personal conduct is not correct, he may issue orders, but they will not be followed. In the diet, never get tired of refined food or finely chopped meat". In the dressing, this gentleman was never arrayed in maroon or scarlet; even at home he would not don red or purple. In appearance, the Master was friendly, yet dignified; he inspired awe, but not fear; he was respectful, yet easy. In shelter and transportation, he did not sleep like a corpse. At home he unbent. If his mat were not straight, he would not sit down. All this reflects that Confucius is an outstanding representative in self-cultivation. He once says, a gentleman has three things to guard against. In the days of thy youth, ere thy strength is not steady, beware of lust. When manhood is reached, in the fullness of strength, beware of strife. In old age, when thy strength is broken, beware of greed. This sums up his experience in self-cultivation in different stages of life. 
Confucius encourages people to learn hard, engage with politics, and pay more attention to self-cultivation. However, it is neither male-dominated thought, nor a thorough denial for female. "Filial piety is the root of Ren (仁)”, where filial piety is not only the business of males, but the business of females. Only girls and servants are hard to train. Draw near to them, they grow unruly; hold them off, they pay you with spite, which does not revile all women, but refers in particular to Nangong (南宫). This suggests the complement of Yin and Yang, where progress decorates retreat and masculinity ornaments femininity.

In the Pre-Qin period, among the ancient cultures which are related with body, besides above-mentioned Confucianist exponents like Confucius and Mencius, Taoism also arises in this period, and important exponents are Lao-tzu and Chuang-Tzu. Lao-tzu is a philosopher who has distinct consciousness for the body. He considers the body to be the rood of anxiety, though it could bring thrills of unexpected pleasure. Favour and disgrace would seem equally to be feared; honour and great calamity, to be regarded as personal conditions (of the same kind) (Dao De Jing 《道德经》 Chapter 13). People have anxiety when they have bodies. What makes me liable to great calamity is my having the body (which I call myself); if I had not the body, what great calamity could come to me? (Dao De Jing Chapter 13) When we closely examine it, we find that the so-called "body" mentioned by Lao-tzu does not mean Tao body as it in "perspective the body at the view of body", but means the human body as described in "perspective the body at the view of mind". Lao-tzu's understanding about the body is more than this, and he links body to running a country. Therefore he who would administer the kingdom, honouring it as he honours his own person, may be employed to govern it, and he who would administer it with the love which he bears to his own person may be entrusted with it (Dao De Jing Chapter 13). Lao-tzu prefers being silent than active in politics, and he says, therefore the sage puts his own person last, and yet it is found in the foremost place; he treats his person as if it were foreign to him, and yet that person is preserved (Dao De Jing Chapter 7). Furthermore, Lao-tzu considers people should retreat when they achieve success and win recognition. Only in this way can people ultimately protect themselves, as he says, when the work is done, and one's name is becoming distinguished, to withdraw into obscurity is the way of Heaven (Dao De Jing Chapter 9). Thus it appears that Lao-tzu understands the body on the premise of the protection of the body. Or fame or life, which do you hold more dear? (Dao De Jing Chapter 44). In his view, nothing overweighs human bodies, including treasures. In other words, nothing is more precious than body, so it is unnecessary to strive for external things at the cost of life.

Confucius advocates masculinity and emphasizes enterprise, while the philosophy of Lao-tsu underlines femininity. For instance, the perception of what is small is (the secret of clear-sightedness); the guarding of what is soft and tender is (the secret of) strength. Who uses well his light, reverting to its (source so) bright, will from his body ward all blight, and hides the unchanging from men's sight (Dao De Jing Chapter 52). Lao-tzu repeats his view in "no perils of the body", and points out the method to achieve this goal, i.e., seeing the small (见小) and Yielding to force (守柔). He is proficient in dialectics, and also quite understand the famous dictum "When things have attained their strong maturity they become old. This may be said to be not in accordance with the Tao: and what is not in accordance with it soon comes to an end" (Dao De Jing Chapter 30). Hence he prefers the infants above all as they are both small (小) and tender (柔). He compares his life to be a baby as following, I alone seem listless and still, my desires having as yet given no indication of their presence. I am like an infant which has not yet smiled. I look dejected and forlorn, as if I had no home to go to (Dao De Jing Chapter 20). What is the infantile state? He says, he who has in himself abundantly the attributes (of the Tao) is like an infant. Poisonous insects will not sting him; fierce beasts will not seize him; birds of prey 
will not strike him. (The infant's) bones are weak and its sinews soft, but yet its grasp is firm. It knows not yet the union of male and female, and yet its virile member may be excited;- - showing the perfection of its physical essence. All day long it will cry without its throat becoming hoarse;- showing the harmony (in its constitution)" (Dao De Jing Chapter 55). The noxious insect and the beast are all formidable things, but they can not hurt infants, that is truth said by Lao-tzu as the soft overcomes the hard, and the weak the strong. Nevertheless, we need the Taoistic theory to reveal the deeper reason, The movement of the Tao by contraries proceeds; and weakness marks the course of Tao's mighty deeds. All things under heaven sprang from it as existing (and named); that existence sprang from it as non-existent (and not named)" (Dao De Jing Chapter 40). Lao-tzu neither denies masculinity and enterprise, nor falls within feminism. Instead, it decorates retreat with progress and ornaments femininity with masculinity. Thus, it can be regarded as the earliest voice of feminism.

Reviewing Confucianism and Taoism from point of view of the body, we can find if it is said the body described in Confucianism more represents a masculine one, the body described in Taoism more represents a feminine one. In contrast with Confucianism, Taoism is inclined to provide the soft Yin for the strong Yang. It is of extraordinary significance to interpret differences between sexes in Confucianism and Taoism. In the view of the body, we can have a radical understanding about the compliment of Confucianism and Taoism in Chinese philosophy. Taoism, especially the doctrine of Lao-tzu, as the earliest feminist, embodies the early protest and criticism for male chauvinism and patriarchy from human philosophers, which is conducive for sexes to maintain a dynamic and reciprocal balance in Chinese culture.

Harmony in Chinese traditional culture provides a philosophical foundation for the construction of harmonious culture, and offers such harmonious modes as the unity of nature and man and Yin and Yang complementing each other. Moreover, as capitalistic material culture currently controls the discourse power, the emergence of a entirely new body culture signals a radical transformation of the thinking mode of modern people, and signifies the material life and production yields to human life and production. It also implies the base of life science alleged by Deleuze, on which the logic of capitalist production is based, is shaking and crumbling, and further means contemporarily people have found a firm foundation for historical reconstruction in the new era.

\section{References}

Kant. (2004). Critique of pure reason (translated by Deng Xiaowang). People’s Publishing House.

ZHANG, X. L. (2002). “Sexual Difference” in Chinese and Western Traditional Philosophy. Jiangsu Social Sciences, 6, 1-9.

ZHANG, Z. L. (2006) The body nature of ancient Chinese religious views. Journal of Humanities, 6, 28-35. 